\title{
Pulmonary tumor diagnosed as an undifferentiated sarcoma with epithelioid features: a case report
}

\author{
Mohamed Réda El Ochi ${ }^{1}$, Mohammed Massine El Hammoumi ${ }^{2}$, Abdelhamid Biyi ${ }^{3}$, Mohamed Allaoui ${ }^{1}$, \\ El Hassane Kabiri ${ }^{2}$, Abderrahman Albouzidi ${ }^{1}$ and Mohamed Oukabli ${ }^{1}$
}

\begin{abstract}
Background: Pulmonary sarcomas are uncommon accounting for $0.5 \%$ of all primary lung cancers. Undifferentiated sarcomas account for up to $20 \%$ of soft tissue sarcomas. A lung tumor revealed to be an undifferentiated sarcoma with epithelioid features has never been reported in the literature.

Case presentation: A 61-year-old white Moroccan man presented with 2 months' history of hemoptysis and dyspnea. Chest computed tomography showed a cystic mass involving the lower field of his right lung evoking first a hydatid cyst. Abdominal computed tomography revealed bilateral adrenal nodules. Surgical resection of the lung mass was performed. On pathological examination, the tumor was cystic containing necrotic material. A histological diagnosis of undifferentiated sarcoma with epithelioid features was made. A positron emission tomography scan showed involvement of his pleura, left colon, adrenal glands, left thigh muscle, and leptomeninges.

Conclusions: Undifferentiated sarcoma with epithelioid features is a rare malignant mesenchymal tumor. Clinical and radiological features are not specific. A differential diagnosis includes sarcomatoid carcinoma, malignant mesothelioma, melanoma, and other epithelioid sarcomas.
\end{abstract}

Keywords: Undifferentiated, Epithelioid, Sarcoma, Lung

\section{Background}

Pulmonary sarcomas are uncommon accounting for $0.5 \%$ of all primary lung cancers. Undifferentiated sarcomas (US) are a heterogeneous group of malignant mesenchymal tumors that do not meet criteria for a welldefined histopathologic entity $[1,2]$. They account for up to $20 \%$ of soft tissue sarcomas and occur at all ages and anatomic sites with no difference between the sexes [1]. Clinical and radiological features are not specific. On morphologic examination, US is divided into pleomorphic, spindle cell, round cell, and epithelioid subsets [1]. Cases of US with epithelioid features (USEF) are rarely reported in the literature [3]. We describe the first case of a lung tumor revealed to be a USEF.

\footnotetext{
* Correspondence: elochi20@yahoo.fr

'Department of Pathology, Mohamed V Military Hospital, Hay Riad, Faculty of Medicine and Pharmacy, Mohammed V University, Rabat, Morocco Full list of author information is available at the end of the article
}

\section{Case presentation Clinical history}

A 61-year-old white Moroccan man with no significant past medical history presented to Mohamed V Military Hospital with hemoptysis and dyspnea which developed 2 months before admission.

\section{Radiologic and histopathologic findings}

Chest computed tomography (CT) showed a cystic mass involving the lower field of his right lung, measuring $5 \times 4.8 \mathrm{~cm}$ without mediastinal adenopathy, evoking first a hydatid cyst. Abdominal CT showed bilateral adrenal nodules compatible with nodular hyperplasia measuring $5.3 \times 4.1 \mathrm{~cm}$ on the right side and $3 \times 2.6 \mathrm{~cm}$ on the left side. Surgical resection of his lung tumor was performed. His postoperative course was uneventful. On pathological examination, the tumor was cystic and contained necrotic material. A histological examination showed nests and sheets of epithelioid cells (Fig. 1). The cells

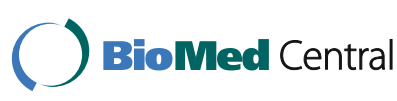

(c) 2016 The Author(s). Open Access This article is distributed under the terms of the Creative Commons Attribution 4.0 International License (http://creativecommons.org/licenses/by/4.0/), which permits unrestricted use, distribution, and reproduction in any medium, provided you give appropriate credit to the original author(s) and the source, provide a link to the Creative Commons license, and indicate if changes were made. The Creative Commons Public Domain Dedication waiver (http://creativecommons.org/publicdomain/zero/1.0/) applies to the data made available in this article, unless otherwise stated. 


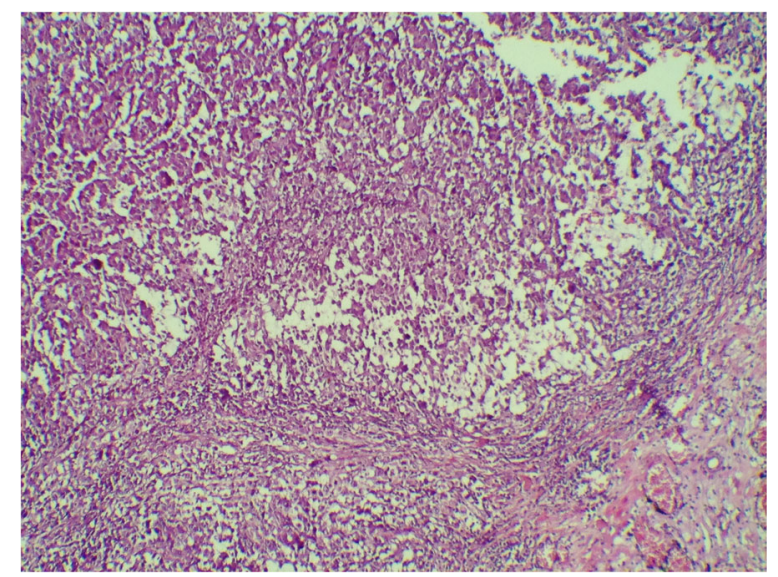

Fig. 1 Cystic wall harboring sheets of tumoral cells. Hematoxylin and eosin stain, original magnification $\times 100$

had an abundant and amphophilic cytoplasm (Fig. 2). The nuclei were vesicular and mitoses were numerous (27 mitoses per 10 high-power fields). The tumor cells displayed diffuse immunoreactivity for vimentin and smooth muscle actin (Fig. 3). CD99 was focally positive. Cytokeratin (CK) AE1/AE3, epithelial membrane antigen (EMA), CK7, CK20, P63, CK34BE12, CK5/6, TTF1, calretinin, WT1, D2-40, desmin, myogenin, H-caldesmon, S100 protein, INI 1, melan A, HMB45, CD34, CD31, MDM2, CD117, DOG1, CD20, CD3, CD30, and placental alkaline phosphatase (PLAP) were all negative. Thus, a diagnosis of USEF grade III FNCLCC (La Fédération Nationale des Centres de Lutte Contre le Cancer; The National Federation of Centers of Cancer Control) was made. The surgical margins were positive. His postoperative course was uneventful.

A positron emission tomography (PET) scan, performed subsequently on the 28th day after surgery, visualized foci

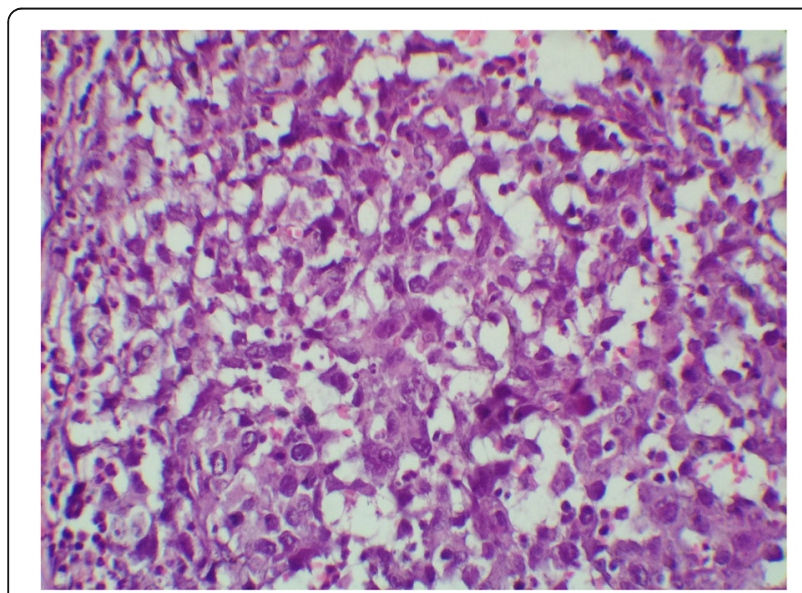

Fig. 2 Tumor cells showing epithelioid features and mild nuclear atypia. Hematoxylin and eosin stain, original magnification $\times 400$

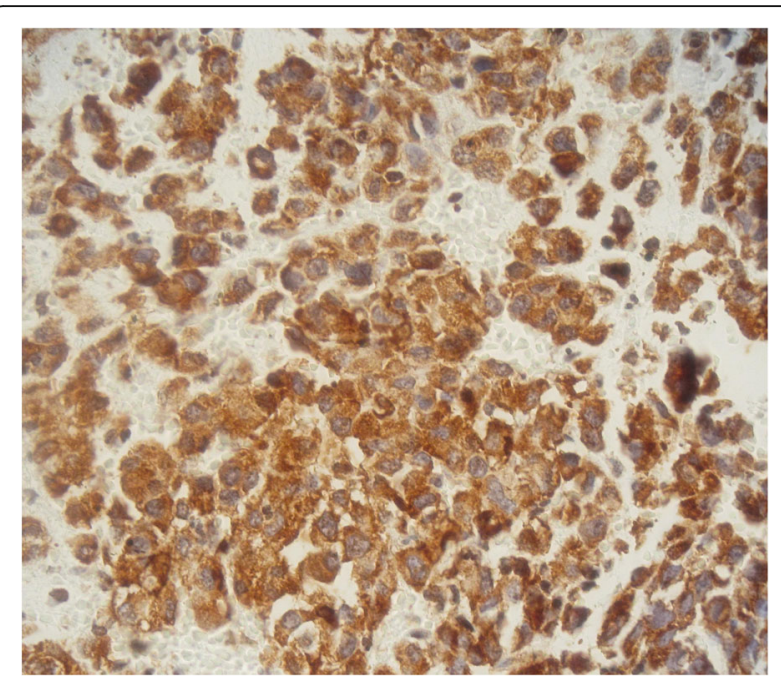

Fig. 3 Smooth muscle actin positivity of the tumor cells. Original magnification $\times 400$

of increased ${ }^{18} \mathrm{~F}$-fluorodeoxyglucose $\left({ }^{18} \mathrm{~F}\right.$-FDG) uptake in his lung tumor (Fig. 4), left colon, adrenal glands, left thigh muscle (Fig. 5), and leptomeninges. A colonoscopy was normal. He is undergoing anti-mitotic chemotherapy.

\section{Discussion}

US are a heterogeneous group of malignant mesenchymal tumors that do not meet criteria for a well-defined histopathologic entity $[1,2]$. It is a diagnosis of exclusion that accounts for $20 \%$ of sarcomas [1]. US occur at all ages and anatomic sites with no difference between the sexes $[1,3]$. Most reported cases are pleomorphic. The epithelioid variant has been rarely reported. Sarcomas of the lung are mainly metastatic [4]; primitive pulmonary

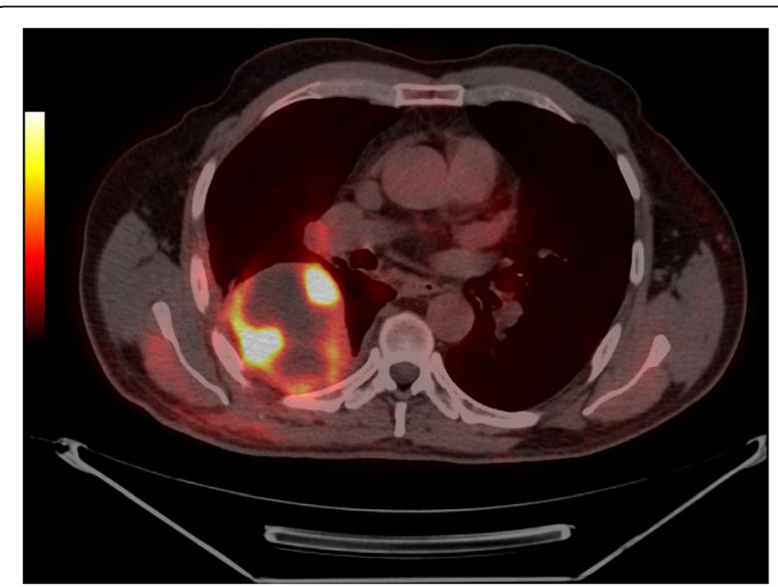

Fig. 4 Axial ${ }^{18}$ F-fluorodeoxyglucose positron emission tomography/ computed tomography fused image showing increased fluorodeoxyglucose uptake in the lung tumor 


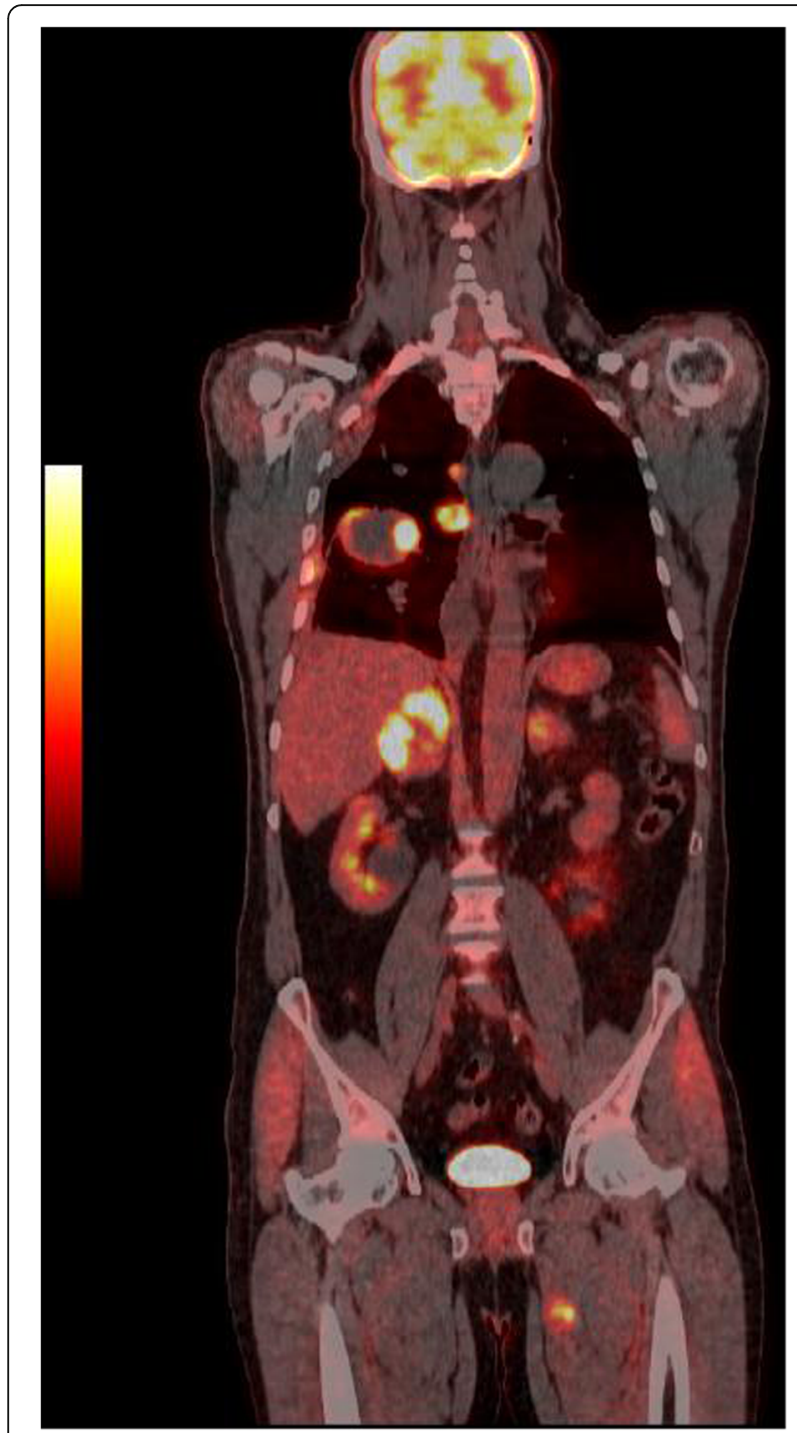

Fig. 5 Coronal 18F-fluorodeoxyglucose positron emission tomography/computed tomography fused image showing hypermetabolic foci in the right lung, mediastinal lymph node, adrenal glands and the left thigh

sarcoma are very uncommon and comprise $0.5 \%$ of all primary lung cancers [5].

Clinical and radiological features of sarcoma are not specific and sometimes asymptomatic $[1,6]$. The macroscopic findings are not distinctive but tumoral necrosis is frequent [1]. On morphologic examination, USEF is composed of nests of cells with amphophilic cytoplasm and large vesicular nuclei [1]. USEF lacks specific immunohistochemical abnormalities; tests for vimentin are positive and tests for smooth muscle actin are sometimes positive [7]. Tests for CKs, desmin, EMA, CD99, and CD34 are generally negative [1]. The differential diagnosis includes sarcomatoid carcinoma, malignant mesothelioma, melanoma, and other sarcomas such us epithelioid sarcoma, leiomyosarcoma, rhabdomyosarcoma, angiosarcoma, epithelioid hemangioendothelioma, dedifferentiated liposarcoma, synovial sarcoma, and metastatic epithelioid gastrointestinal stromal tumor $[1,4,6]$.

The treatment of USEF is similar to epithelioid sarcoma [3]. In localized form, the treatment is based on surgical excision followed by adjuvant doxorubicinbased chemotherapy and sometimes radiotherapy [3]. The treatment of metastasizing tumors is based mainly on chemotherapy. The prognosis of USEF is poor and the 5 -year survival is $52 \%$ [3]. Recurrences and metastases occur in $25 \%$ and $35 \%$ of cases respectively [3].

\section{Conclusions}

In summary, USEFs are extremely rare malignant sarcomas. They can occur at all ages and anatomic sites. The epithelioid variant has been rarely reported. The diagnosis is based on morphological and immunohistochemical analyses that allow exclusion of differential diagnoses. In our case, the location posed additional diagnostic difficulties.

\section{Abbreviations \\ CK: Cytokeratin; CT: Computed tomography; EMA: Epithelial membrane antigen; FDG: Fluorodeoxyglucose; PET: Positron emission tomography; PLAP: Placental alkaline phosphatase; US: Undifferentiated sarcoma; USEF: Undifferentiated sarcoma with epithelioid features}

\section{Acknowledgements}

None.

\section{Funding}

None.

\section{Availability of data and materials Not applicable.}

\section{Authors' contributions \\ MRE, MME, and MA analyzed and interpreted the patient data, drafted the manuscript, and made the figures. AA and MO performed the histological examination, proposed the study, supervised MRE, and revised the manuscript. $A B$ and $E K$ have made substantial contributions to analysis and interpretation of patient data. All authors read and approved the final manuscript.}

\section{Competing interests}

The authors declare that they have no competing interests.

\section{Consent for publication}

Written informed consent was obtained from the patient for publication of this case report and any accompanying images. A copy of the written consent is available for review by the Editor-in-Chief of this journal.

Ethics approval and consent to participate Not applicable.

\section{Author details}

'Department of Pathology, Mohamed V Military Hospital, Hay Riad, Faculty of Medicine and Pharmacy, Mohammed V University, Rabat, Morocco.

${ }^{2}$ Department of Thoracic Surgery, Mohamed V Military Hospital, Hay Riad,

Faculty of Medicine and Pharmacy, Mohammed V University, Rabat, Morocco. ${ }^{3}$ Department of Nuclear Medicine, Mohamed V Military Hospital, Hay Riad,

Faculty of Medicine and Pharmacy, Mohammed V University, Rabat, Morocco.

Received: 24 November 2015 Accepted: 6 September 2016 Published online: 03 October 2016 


\section{References}

1. Fletcher CDM, Chibon F, Merlens F. Undifferentiated/unclassified sarcomas. World Health Organization Classification of tumours of soft tissue and bone. Lyon: IARC Press; 2013. p. 236-8.

2. Alaggio R, Bisogno G, Rosato A, et al. Undifferentiated sarcoma: does it exist? A clinicopathologic study of 7 pediatric cases and review of literature. Hum Pathol. 2009;40:1600-10.

3. Sakharpe A, Lahat G, Gulamhusein T, Liu P, Bolshakov S, Nguyen T, et al. Epithelioid sarcoma and unclassified sarcoma with epithelioid features: clinicopathological variables, molecular markers, and a new experimental model. Oncologist. 2011;16:512-22.

4. Franks TJ, Galvin JR. Sarcomatoid carcinoma of the lung: histologic criteria and common lesions in the differential diagnosis. Arch Pathol Lab Med. 2010;134:49-54.

5. Falkenstern-Ge RF, Kimmich M, Grabner A, et al. Primary pulmonary synovial sarcoma: a rare primary pulmonary tumor. Lung. 2014;192:211-4.

6. Litzky LA. Pulmonary sarcomatous tumors. Arch Pathol Lab Med. 2008;132: 1104-17.

7. Turhan N, Ozgüler Z, Cağlı K, Cağlı K, Gölbaşı Z. Primary cardiac undifferentiated sarcoma: role of intraoperative imprint cytology and frozen section of two cases. Cardiovasc Pathol. 2011;20(4):232-7.

\section{Submit your next manuscript to BioMed Central} and we will help you at every step:

- We accept pre-submission inquiries

- Our selector tool helps you to find the most relevant journal

- We provide round the clock customer support

- Convenient online submission

- Thorough peer review

- Inclusion in PubMed and all major indexing services

- Maximum visibility for your research

Submit your manuscript at www.biomedcentral.com/submit 